\title{
Klotho Inhibits Proliferation in a RET Fusion Model of Papillary Thyroid Cancer by Regulating the Wnt/ $\beta$-Catenin Pathway
}

\author{
Qiong $\mathbf{W u}^{\mathrm{l}, *}$ \\ Liang Jiang ${ }^{2} *$ \\ Jiang $\mathrm{Wu}^{3}$ \\ HaiFang Dong' \\ Yaping Zhao $\mathbb{D}^{4}$
}

\begin{abstract}
'Medical Examination Center, Huai'an Second People's Hospital, The Affiliated Huai'an Hospital of XuZhou Medical University, Huai'an, 22300I, People's Republic of China; ${ }^{2}$ Department of EarNose-Throat, Qingdao Women and Children's Hospital, Qingdao, 266000, People's Republic of China; ${ }^{3}$ Clinic Transfusion Room, Huai'an Second People's Hospital, The Affiliated Huaian Hospital of XuZhou Medical University, Huai'an, 22300I, People's Republic of China; ${ }^{4}$ Clinic Transfusion Room, Nanjing Gaochun People's Hospital, Nanjing, 2II300, People's Republic of China

*These authors contributed equally to this work
\end{abstract}

Correspondence: Yaping Zhao Clinic Transfusion Room, Nanjing Gaochun People's Hospital, No. 53 Maoshan Road, Gubai Street, Gaochun District, Nanjing, 2I I300, People's Republic of China

Tel +86-13770897235

Email ypzgaochun@163.com
Purpose: We aimed to investigate the mechanisms of action on Klotho that underlie cancer development in RET fusion models of human papillary thyroid cancer (PTC).

Materials and Methods: Normal Nthy-ori 3-1 thyroid cells and two PTC cell lines (BHP10-3 and TPC-1), which were used as RET fusion models of PTC, were used to study Klotho. Klotho expression was analyzed by Western blotting. Klotho overexpression cell lines were constructed using the two types of PTC cells. Cell proliferation and apoptosis were assessed. Western blotting was used to detect the expression of proteins in the Wnt/ $\beta$ catenin pathway. In addition, an activator and an inhibitor of the $\mathrm{Wnt} / \beta$-catenin pathway were used to confirm that Klotho regulates the pathway in PTC cells. Mice were used to analyze the in vivo effect of Klotho on tumor growth and the Wnt/ $\beta$-catenin pathway.

Results: In BHP10-3 and TPC-1 cells, Klotho expression was low. After Klotho overexpression, the cell proliferation was significantly suppressed and apoptosis was significantly increased $(\mathrm{p}<0.05)$. Wnt1, $\beta$-catenin, and CyclinD1 expression were also significantly decreased after Klotho overexpression $(p<0.05)$. Administration of the Wnt/ $\beta$-catenin pathway activator attenuated the effect of Klotho overexpression $(p<0.05)$. In vivo, the tumor growth was suppressed, and apoptosis of the cancer cells in the tumors were increased after Klotho overexpression. However, injection of the $\mathrm{Wnt} / \beta$-catenin pathway activator attenuated the effects of Klotho overexpression.

Conclusion: Klotho inhibits cell proliferation in RET fusion models of PTC by inhibiting the $\mathrm{Wnt} / \beta$-catenin pathway, providing a potential target for developing treatment for PTC.

Keywords: RET/PTC, Klotho, Wnt/ $\beta$-catenin pathway, proliferation, apoptosis

\section{Introduction}

In the past few decades, the number of diagnosed thyroid carcinomas has increased rapidly, and $18-58 \%$ of cases are multifocal. ${ }^{1}$ Surgery aims to remove non-metastatic thyroid cancer, and radiation and chemotherapy are also used to treat thyroid cancer. There are five subtypes of thyroid cancer: papillary thyroid cancer (PTC) and follicular thyroid cancer (FTC) are the most common subtypes, and medullary thyroid cancer (MTC), anaplastic thyroid cancer (ATC), and poorly differentiated thyroid carcinomas (PDTCs) are rare subtypes. ${ }^{2}$ The survival rates of patients with thyroid carcinomas vary greatly, depending on the tissue type and degree of differentiation. ${ }^{3}$ Schweppe et al reported that the PTCderived TPC-1 and BHP10-3 cell lines both harbor the RET/PTC1 rearrangement. ${ }^{4}$ In recent years, identifying genetic changes and conducting 
genetic testing in thyroid carcinomas has provided useful information for clinical therapy.

Klotho is a five-exon gene located at chromosome $13 q 12$ in humans. It elicits anti-inflammatory, anti-tumor, and anti-aging effects via the regulation of intracellular signaling pathways. ${ }^{5}$ As an anti-tumor protein, Klotho is considered as a major factor underlying the pathogenesis of several cancers, such as breast cancer, ${ }^{6}$ colorectal cancer, ${ }^{7}$ and pancreatic cancer. ${ }^{8}$ Klotho acts as a circulating hormone that inhibits cancer cell proliferation and migration by regulating tumor-related signal pathways, such as the $\mathrm{Wnt} / \beta$-catenin and phosphoinositide 3-kinase (PI3K)/Akt pathways. ${ }^{9}$ In highly malignant thyroid cancers, $\alpha$-Klotho expression was negative or very weak. ${ }^{10}$ However, the mechanism of action of Klotho has not been confirmed in a RET fusion model of PTC.

The Wnt/ $\beta$-catenin pathway is involved in the cell cycle, proliferation, polarity, and survival. ${ }^{11}$ It is well known that this pathway regulates many key aspects of cancer development, including in thyroid carcinoma. ${ }^{12,13}$ Much evidence shows that the Wnt/ $\beta$-catenin pathway promotes cancer cell metastasis and survival, enhancing tumor angiogenesis. ${ }^{14,15}$ In PTC, the Wnt/ $\beta$-catenin pathway plays a primary role in invasion and metastasis, and its alteration is a late event in thyroid cell transformation. ${ }^{13}$ However, the molecular mechanism of action of Klotho regarding the Wnt/ $\beta$-catenin pathway in PTC involving RET fusion remain unclear.

In this study, the expression and biological functions of Klotho in RET fusion models of PTC (involving BHP10-3 and TPC- 1 cells), and its role in regulating the $\mathrm{Wnt} / \beta$ catenin pathway, were elucidated. The results might provide research directions for developing treatment for PTC.

\section{Materials and Methods}

\section{Cell Culture}

We obtained the normal thyroid cell line Nthy-ori 3-1 (JN2993, Shanghai Ji Ning Industrial Co., Ltd., China) and two PTC cell lines, TPC-1 (CC-Y1522, Shanghai Enzyme Research Biotechnology Co., Ltd., China) and BHP10-3 (Gibco, Carlsbad, CA, USA), which were both used as RET fusion models of PTC. The TPC-1 cells were cultured in Dulbecco's Modified Eagle Medium (DMEM) with 10\% fetal bovine serum (FBS) and 1\% penicillin-streptomycin solution (Sigma-Aldrich, St. Louis, MO, USA). The other cells were maintained in Roswell Park Memorial Institute (RPMI)-1640 medium (Gibco, ThermoFisher, NY, USA) with 10\% FBS (Sigma-Aldrich, St. Louis, MO, USA), 100 $\mathrm{U} / \mathrm{mL}$ penicillin, and $100 \mathrm{mg} / \mathrm{mL}$ streptomycin. The cells were cultured at $37^{\circ} \mathrm{C}$ in $5 \% \mathrm{CO}_{2}$.

\section{Cell Grouping}

The PTC cell lines TPC-1 and BHP10-3 were divided into three groups: the control group, Klotho empty vector group, and Klotho overexpression group. In the control group, the cells were cultured as normal. In the Klotho empty vector group (negative control [NC]), the cells were transfected with empty vector using Lipofectamine 3000 reagent (Invitrogen) for $72 \mathrm{~h}$. In the Klotho overexpression group (Klotho), the cells were transfected with an expression plasmid encoding Klotho (F: 5'-CGGA ATTCATGCCAGCCCGCG-3'; R: 5'-CGGGATCCTTATT TATAACGTCTCCGGCC-3') using Lipofectamine 3000 reagent for $72 \mathrm{~h}$. The empty vector and expression plasmid encoding Klotho were purchased from Gene Technologies (Shanghai, China).

To study the effect of Klotho on the Wnt/ $\beta$-catenin pathway in PTC cells, another set of cancer cells were divided into four groups: the control group, Klotho group, Wnt pathway inhibitor group (Dickkopf-related protein 1 [DKK1]), and Klotho overexpression and Wnt pathway activator group (Klotho overexpression $+\mathrm{LiCl}[\mathrm{K}+\mathrm{L}]$ ). In the DKK1 group, the cells were treated with $200 \mathrm{ng} /$ $\mathrm{mL}$ DKK- $1 .{ }^{16}$ In the $\mathrm{K}+\mathrm{L}$ group, cells were treated with Klotho overexpression plasmid and $20 \mathrm{mM} \mathrm{LiCl} .{ }^{17}$

\section{RT-PCR}

Total RNA was isolated from the cultured PTC cells using TRIzol reagent (Takara, Dalian, China). Then the RNA was reverse transcribed into cDNA using a PrimeScript ${ }^{\mathrm{TM}}$ RT Master Mix (TaKaRa, Japan). RT-PCR was performed using Mastercycler ${ }^{\circledR}$ Nexus X2 (Eppendorf, Hamburg, Germany) using the following conditions: $95^{\circ} \mathrm{C}$ for 10 min, 35 cycles at $95^{\circ} \mathrm{C}$ for $15 \mathrm{~s}$, and $60^{\circ} \mathrm{C}$ for 60 s. Relative expression was analyzed using the $2^{-\Delta \Delta C t}$ method. The primer sequences were as follows: Klotho, forward: 5'-ACCAAGAAGAGGAAATC-3', reverse: 5'TACCCAGAGGGAGAATC-3'. GAPDH, forward: 5'AGCCCATCACCATCTTCCAG-3', reverse: 5'-CCTG CTTCACCACCTTCTTG-3'.

\section{Cell Counting Kit (CCK)-8 Assay}

Cells in the logarithmic growth phase were seeded into 96well plates at a concentration of $2 \times 10^{4} / \mathrm{mL}$ and $100 \mu \mathrm{L}$ of medium was added to each well. After culture for $24 \mathrm{~h}$ at 
$37^{\circ} \mathrm{C}$ in $5 \% \mathrm{CO}_{2}, 10 \mu \mathrm{L}$ CCK-8 solution was added to each well (Tonghua Institute of Chemistry, Japan) and mixed well before further culture for $4 \mathrm{~h}$. The absorbance (optical density [OD]) of each well at $450 \mathrm{~nm}$ was measured using a microplate reader. Cell survival rate $(\%)=$ $\left[\left(\mathrm{OD}_{\text {(experiment) }}-\mathrm{OD}_{\text {(control) }}\right) /\left(\mathrm{OD}_{\text {(control) }}-\mathrm{OD}_{\text {(blank) }}\right)\right] \times 100 \%$.

\section{Plate Colony Formation Assay}

The concentration of the cells was adjusted to $250 / \mathrm{mL}$, and $2 \mathrm{~mL}$ of the cell suspension was added to each well of a six-well plate. The cells were incubated at $37^{\circ} \mathrm{C}$ in $5 \%$ $\mathrm{CO}_{2}$ for 2-3 weeks, and the medium was replaced with fresh medium every 3 days. The cells were fixed with methanol, $1 \mathrm{~mL}$ GEMSA solution was added to each well, and the cells were stained for $30 \mathrm{~min}$. The cells were washed with ultrapure water twice, the water around the dish was then removed using a filter, and photos were taken.

\section{Transwell Assay}

Cells in the logarithmic growth phase were digested with $0.25 \%$ trypsin and the concentration was adjusted to $4 \times 10^{5}$ cells $/ \mathrm{mL}$. In the upper transwell chamber, $100 \mu \mathrm{L}$ of cell suspension was added and cultured at $37^{\circ} \mathrm{C}$ for $4 \mathrm{~h}$, while $600 \mu \mathrm{L}$ RPMI-1640 medium was added to the lower chamber. The cells were incubated at $37^{\circ} \mathrm{C}$ in $5 \% \mathrm{CO}_{2}$ for $24 \mathrm{~h}$. After washing twice with phosphate-buffered saline (PBS), the membranes were fixed with 5\% glutaraldehyde for $30 \mathrm{~min}$ at $4{ }^{\circ} \mathrm{C}$, washed with PBS, and stained with $0.1 \%$ crystal violet (Solarbio, Beijing, China) for 30 min. The results were observed under a light microscope (Olympus Corporation, Tokyo, Japan).

\section{Flow Cytometry}

After treatment, the cells were cultured for $24 \mathrm{~h}$ and then collected. The cells were washed with precooled $1 \times$ PBS $\left(4^{\circ} \mathrm{C}\right)$, centrifuged at $1000 \mathrm{rpm}$ for $5-10 \mathrm{~min}$, and washed again. Thereafter, $300 \mu \mathrm{L}$ of $1 \times$ Binding Buffer was added to suspend the cells. Next, $5 \mu \mathrm{L}$ annexin V-allophycocyanin (APC) was added and mixed. The cells were then incubated for $15 \mathrm{~min}$ at room temperature without light. Next, $5 \mathrm{~min}$ before loading, $5 \mu \mathrm{L}$ of propidium iodide (PI) stain was added, and then $200 \mu \mathrm{L}$ of $1 \times$ Binding Buffer was added. The samples were assessed by flow cytometry (Beckman Coulter, Brea, CA, USA) and the data were analyzed by CellQuest software (BD Bioscience, San Diego, CA).

\section{Western Blotting}

The cells or tumor tissues were lysed using lysozyme solution (M052447, MREDA), and the protein concentration in the cells was measured using a bicinchoninic acid (BCA) kit (G3522, GBCBIO). The protein samples ( $40 \mu \mathrm{g})$ were then subjected to $10 \%$ sodium dodecyl sulphate-polyacrylamide gel electrophoresis (SDS-PAGE) and transferred onto polyvinylidene difluoride (PVDF) membranes. The membranes were blocked with 5\% skim milk. They were then incubated at $4^{\circ} \mathrm{C}$ overnight with the following primary polyclonal antibodies diluted with Tris-buffered saline with Tween 20 (TBST) containing 3\% bovine serum protein: Klotho (1:1000, orb336494, Biorbyt, Cambridge, UK), Bax (1:500, orb224426, Biorbyt, Cambridge, UK), Bcl-2 (1:500, orb226346, Biorbyt, Cambridge, UK), cleaved caspase-3 (1:500, orb126597, Biorbyt, Cambridge, UK), Wnt1 (1:500, orb227963, Biorbyt), $\beta$-catenin (1:500, ER0805, HUABIO), CyclinD1 (1:500, orb7738, Biorbyt, Cambridge, UK), and $\beta$-actin (1:2000, orb178392, Biorbyt, Cambridge, UK). After rewarming, horseradish peroxidaselabeled goat anti-mouse IgG (1:1000, orb43295, Biorbyt) was added for $1 \mathrm{~h}$. The membranes were then washed and the antibodies were detected using enhanced chemiluminescence (ECL) substrate for 3-5 min. Protein expression was standardized to the level of $\beta$-actin. The band intensity was scanned and quantified using ImageJ software (National Institutes of Health [NIH]).

\section{Animals}

Forty-eight specific-pathogen-free Balb/c female nude mice (16-18 g, 4 weeks old) were purchased from Charles River Laboratories (license number: SCXK (Beijing) 20160006). Each mouse was fed in an independent, aseptic, and ventilated isolation cage in a laminar air flow purification room where the temperature $\left(26-28^{\circ} \mathrm{C}\right)$ and humidity (relative humidity $40-60 \%$ ) were kept constant. The feed, drinking water, and bedding material were sterilized. Animal experiments followed the NIH guidelines (NIH pub. no. 85-23, revised 1996), and the experiments were approved by the Animal Protection and Use Committee of Huai'an Second People's Hospital.

\section{Construction of Nude Mice with Xenograft Tumors}

Cells in the logarithmic growth phase were digested with $0.25 \%$ trypsin. The concentration was adjusted to $5 \times 10^{7} /$ $\mathrm{mL}$ and $0.1 \mathrm{~mL}$ was inoculated into the right forelimb 
close to the soft skin on the back of 24 nude mice. The mice were randomly divided into four groups (six mice/ group): (1) control group: mice were injected with normal cultured TPC-1 and BHP10-3 cells; (2) Klotho group (Klotho): mice were injected with TPC-1 and BHP10-3 cells, which were treated with the Klotho overexpression plasmid; (3) Wnt pathway inhibitor group (DKK-1): mice were injected with normal cultured TPC-1 and BHP10-3 cells and then intraperitoneally injected with $50 \mu \mathrm{g} / \mathrm{kg}$ DKK-1 every day; ${ }^{18}$ (4) Klotho overexpression and Wnt pathway activator group $(\mathrm{K}+\mathrm{L})$ : mice were injected with Klotho-overexpressing TPC-1 and BHP10-3 cells and then intraperitoneally injected with $15 \mathrm{mg} / \mathrm{kg} \mathrm{LiCl}$ every day. ${ }^{17}$

\section{Tumor Volume Calculation}

Vernier calipers were used to measure the terminology (L) and short diameter (W) every 7 days to calculate the tumor volume. Tumor volume $(\mathrm{V})=($ terminology $\times$ short diameter $\left.^{2}\right) / 2$. After 35 days, the mice were anesthetized by intraperitoneal injection of $0.6 \%$ pentobarbital sodium $(40 \mathrm{mg} / \mathrm{kg})$. The mice were sacrificed by neck dissection. The tumor tissues were collected, weighed, fixed in $4 \%$ paraformaldehyde, and embedded in paraffin for $24 \mathrm{~h}$. A portion of each tissue was placed in a freezer tube and stored at $-80^{\circ} \mathrm{C}$.

\section{Immunochemistry}

After routine sectioning of the tumor tissues, the sections were dewaxed with xylene, hydrated with gradient ethanol solution, and then $3 \% \mathrm{H}_{2} \mathrm{O}_{2}$ in methanol was used for endogenous peroxidase inactivation for $20 \mathrm{~min}$. Hightemperature antigen retrieval in citrate buffer $(\mathrm{pH} 6.0)$ was then performed for 10 min followed by adding 5\% bovine serum albumin for $20 \mathrm{~min}$. Rabbit anti-human Ki67 polyclonal antibodies (1:200, orb88614, Biorbyt, Cambridge, UK) were added and the tissues were incubated overnight at $4^{\circ} \mathrm{C}$. After rewarming, horseradish peroxidase-labeled goat anti-rabbit secondary $\operatorname{IgG}$ (1:1000, ABIN101988, linats-online, Germany) was added. The sections were stained, redyed, dehydrated, cleared, and sealed as usual. After observation under a $\times 400$ optical microscope (Olympus Corporation), Aperio ImageScope 11.1 software was used to analyze the results, which were expressed as the percentage (\%) of positive cells.

\section{Statistical Analysis}

SPSS 19.0 was used for statistical analysis. The results are presented as mean $\pm \mathrm{SD}$. The data were normally distributed. The $t$ test was used to compare pairs of groups. Analysis of variance (ANOVA) and Tukey's post-hoc test were used to compare multiple groups. $\mathrm{P}<0.05$ indicated statistically significant differences.

\section{Results}

\section{Effect of Klotho on Cell Proliferation in RET Fusion Models of PTC}

As shown in Figure 1A, Klotho expression in Nthy-ori 3-1, TPC-1, and BHP10-3 cells was analyzed by Western blotting. Compared to the Nthy-ori 3-1 cells, Klotho expression in the PTC cells was significantly decreased $(p<0.05)$. Further, Klotho overexpression was used to analyze the effect of Klotho on cell proliferation in the RET fusion models of PTC. Klotho mRNA expression was significantly increased after transfecting the Klotho overexpression plasmid $(\mathrm{p}<0.05$, Figure 1B). The cell viabilities were analyzed by CCK- 8 assays and the results showed the TPC-1 and BHP10-3 cell viabilities were significantly decreased after Klotho overexpression compared to the control group ( $\mathrm{p}<0.05$, Figure 1C). The colony numbers (Figure 1D) and migrated cell numbers (Figure 1E) were also significantly decreased in the Klotho group compared to the control group $(p<0.05)$. These data suggested that Klotho inhibited the cell proliferation in the RET fusion models of PTC.

\section{Effect of Klotho on Wnt/ $\mathrm{W}$-Catenin Pathway in RET Fusion Models of PTC}

The effect of Klotho on apoptosis in the RET fusion models of PTC was analyzed by flow cytometry (Figure 2A). Apoptosis was significantly increased in the Klotho group compared to the control group $(\mathrm{p}<0.05)$. Apoptosisrelated proteins were also measured by Western blotting (Figure 2B). The Bax and cleaved caspase-3 proteins were significantly increased, but the Bcl-2 protein was significantly decreased, in the Klotho group compared to the control group $(\mathrm{p}<0.05)$. Further, Wnt $/ \beta$-catenin pathwayrelated protein expression was observed in each group by Western blotting (Figure 2C). The results showed that Wnt1, $\beta$-catenin, and CyclinD1 expression was significantly inhibited in the Klotho group compared to the control group $(\mathrm{p}<0.05)$. These data revealed that Klotho 
A

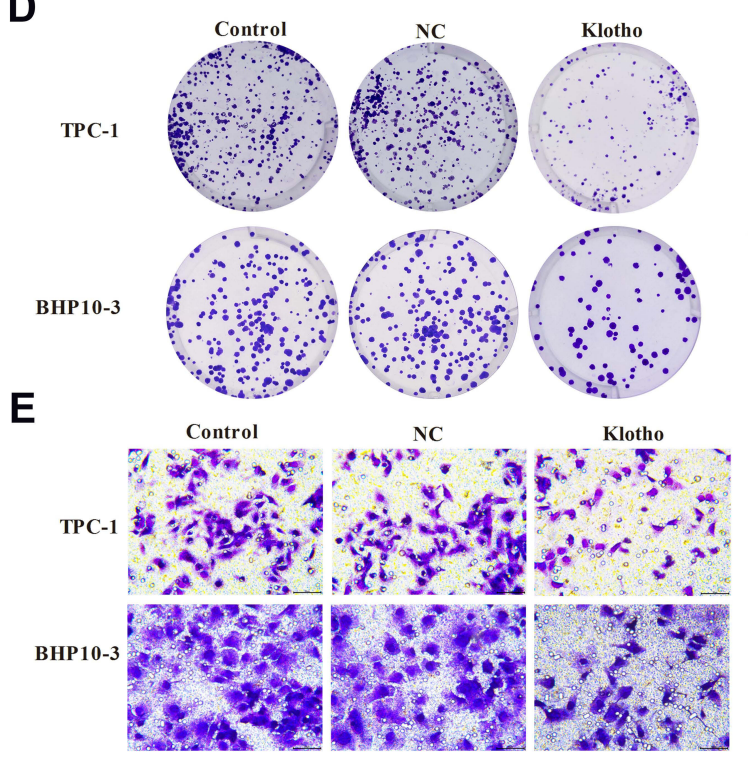

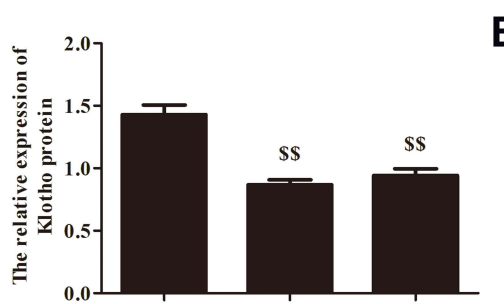

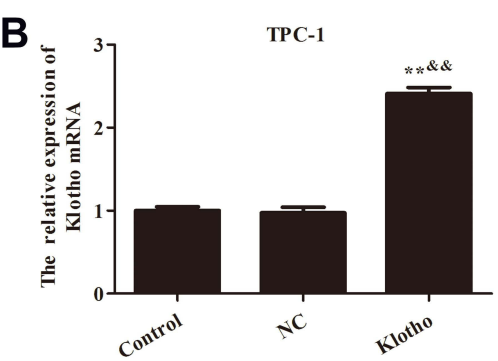

C
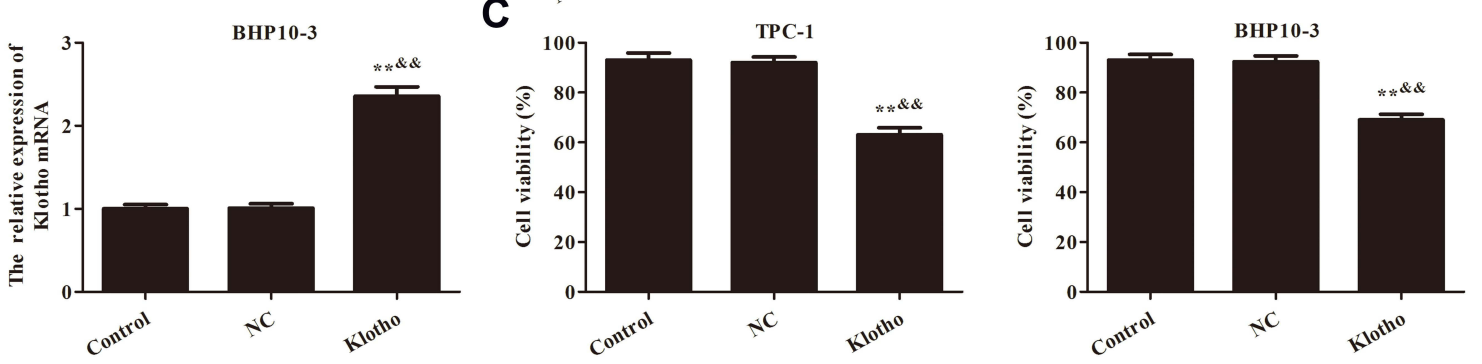
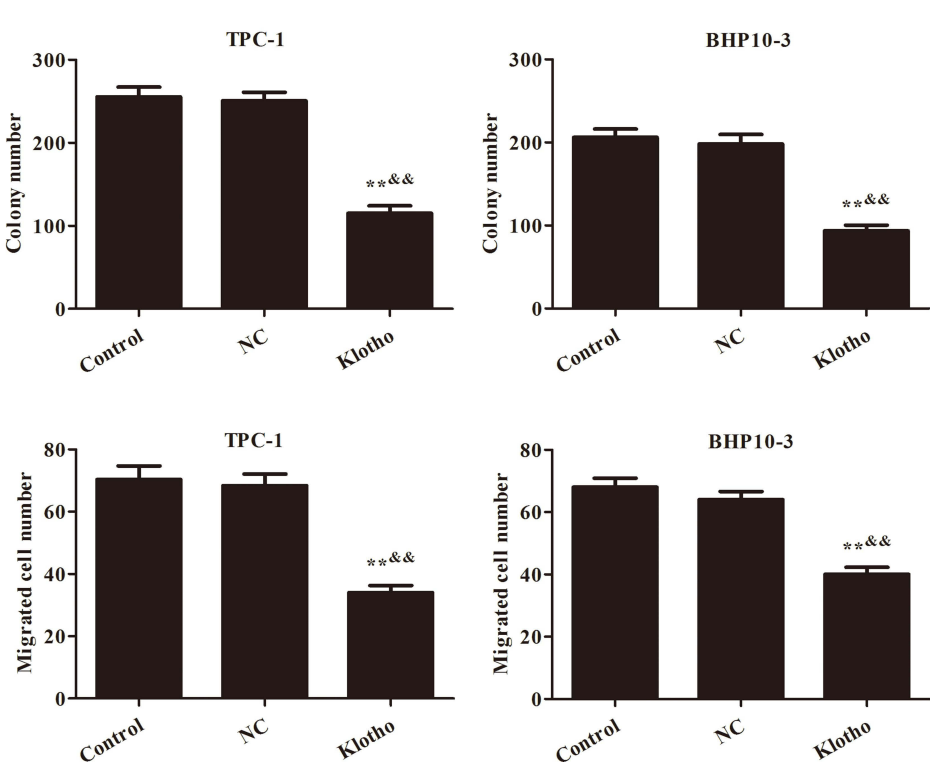

Figure I Effect of Klotho on proliferation of TPC-I and BHPI0-3 cells. (A) Klotho expression in Nthy-ori 3-I, TPC-I, and BHPI0-3 cells was analyzed by Western blotting. (B) Klotho mRNA expression in TPC-I and BHPI0-3 cells in each group was analyzed by RT-PCR. (C) TPC-I and BHPI0-3 cell viabilities were analyzed by Cell Counting Kit (CCK)-8 assay. (D) TPC-I and BHPI0-3 cell proliferation was analyzed by plate colony formation assay. (E) TPC-I and BHPI0-3 cell migration was analyzed by Transwell assay $(\times 400)$. Compared to the Nthy-ori 3-I group, ${ }^{\$ \$} \mathrm{p}<0.0 \mathrm{I}$; Compared to the control group, ${ }^{* *} \mathrm{p}<0.0 \mathrm{I}$; Compared to the NC group, ${ }^{\& \&} \mathrm{p}<0.0 \mathrm{I}$. Experiments were repeated three times and data are presented as mean \pm SD.

played a role in the RET fusion models of PTC via the Wnt/ $\beta$-catenin pathway.

\section{Klotho Inhibits Cell Proliferation in RET Fusion Models of PTC via the Wnt/ $\beta$ - Catenin Pathway}

To study whether Klotho inhibits cell proliferation in the RET fusion models of PTC via the Wnt/ $\beta$-catenin pathway, a Wnt pathway inhibitor (DKK-1) and a Wnt pathway activator $(\mathrm{LiCl})$ were used. As shown in Figure 3A,
Wnt1, $\beta$-catenin, and CyclinD1 expression was significantly decreased in the other groups compared to the control group $(\mathrm{p}<0.05)$. Interestingly, these proteins were significantly increased in the $\mathrm{K}+\mathrm{L}$ group compared to the Klotho group or the DKK-1 group $(\mathrm{p}<0.05)$. CCK-8 (Figure 3B), plate colony formation (Figure $3 \mathrm{C}$ ), and transwell (Figure 3D) assays were used to analyze the proliferation of the two PTC cell lines. As a result, we found that, compared to the control group, the cell viabilities, colony numbers, and migrated cell numbers were significantly reduced in the other groups 
A
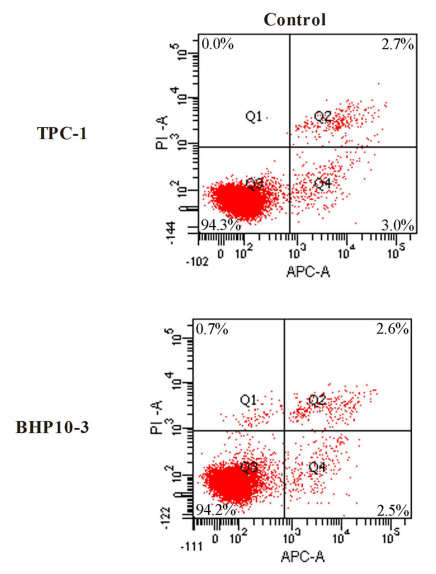
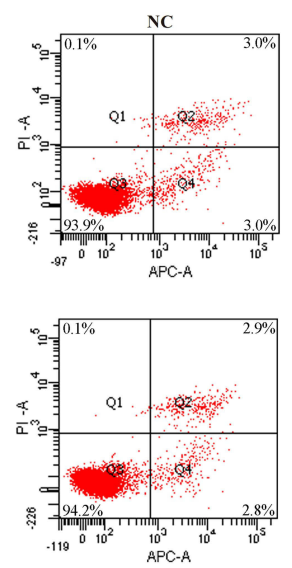
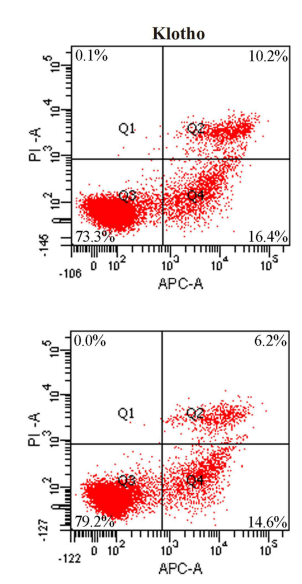

B
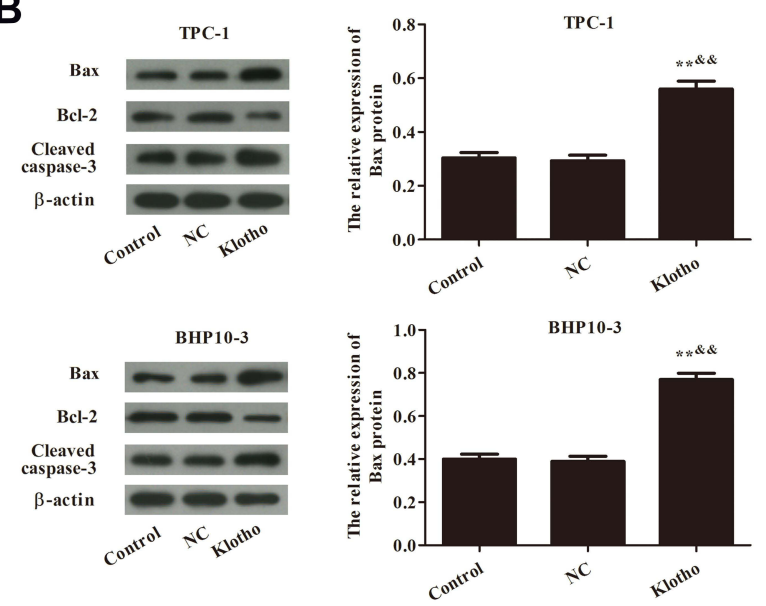

C
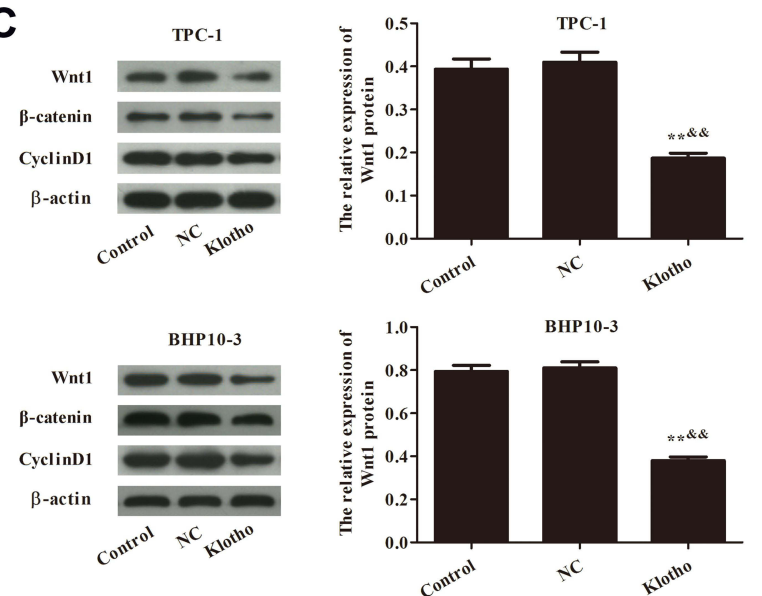
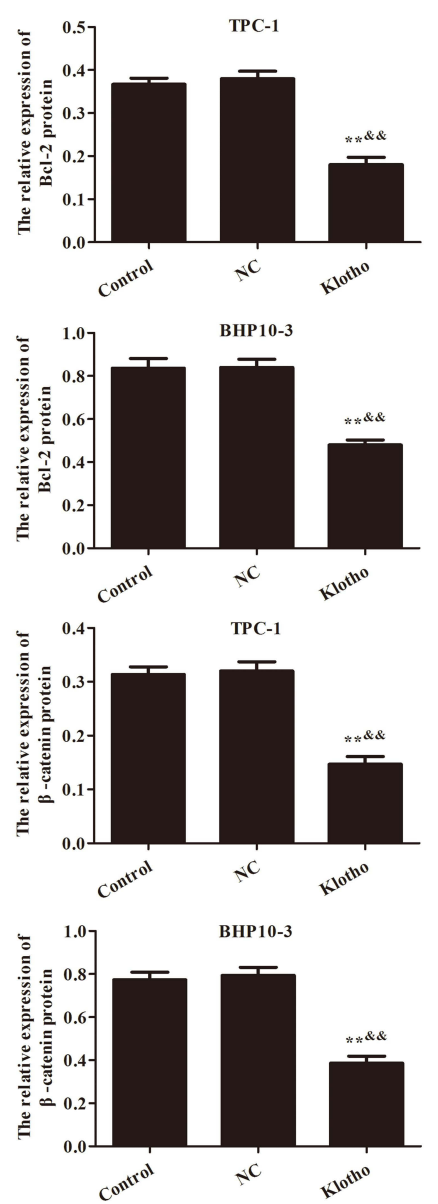
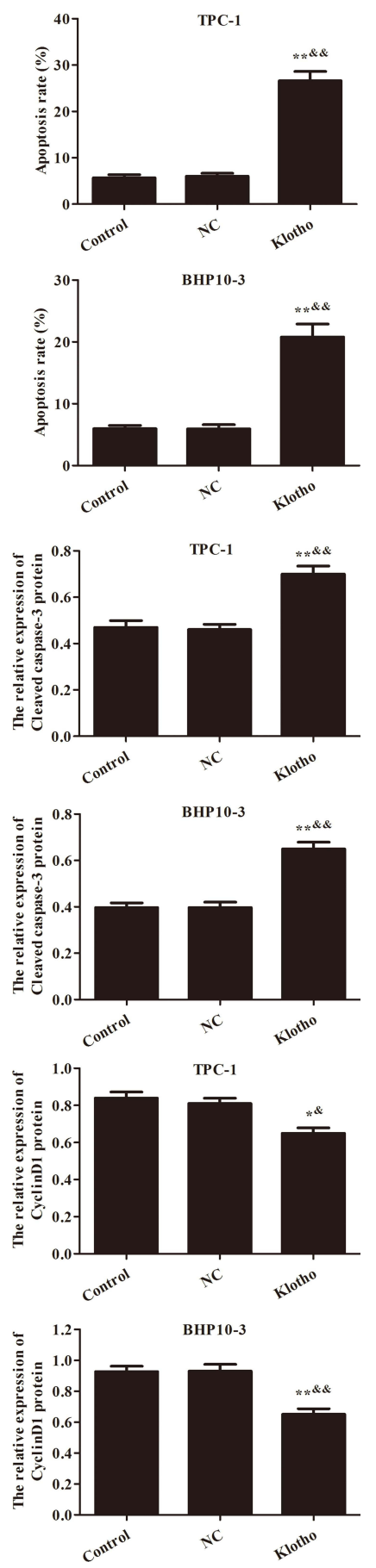

Figure 2 Effect of Klotho on apoptosis and Wnt/ $\beta$-catenin pathway in TPC-I and BHPI0-3 cells. (A) Apoptosis was analyzed by flow cytometry. (B) Apoptosis-related proteins Bax, Bcl-2, and cleaved caspase-3 were analyzed by Western blotting. (C) Wnt/ $\beta$-catenin pathway-related proteins Wnt I, $\beta$-catenin, and CyclinDI were analyzed by Western blotting. Compared to the control group, ${ }^{*} \mathrm{p}<0.05,{ }^{* *} \mathrm{p}<0.01$; Compared to the $\mathrm{NC}$ group, ${ }^{\mathrm{P}} \mathrm{p}<0.05,{ }^{\& \&} \mathrm{p}<0.0 \mathrm{I}$. Experiments were repeated three times and data are presented as mean \pm SD.

$(p<0.05)$. Compared to the Klotho group, these variables were significantly increased in the $\mathrm{K}+\mathrm{L}$ group $(\mathrm{p}<0.05)$. These data revealed that Klotho regulated the $\mathrm{Wnt} / \beta$ catenin pathway and thereby affected cell proliferation in the RET fusion models of PTC.
Klotho Regulates Apoptosis in RET Fusion Models of PTC via the Wnt/ $\beta$ Catenin Pathway

Apoptosis was analyzed by flow cytometry (Figure 4A). As shown in Figure 4A, the apoptosis rates were significantly 
A
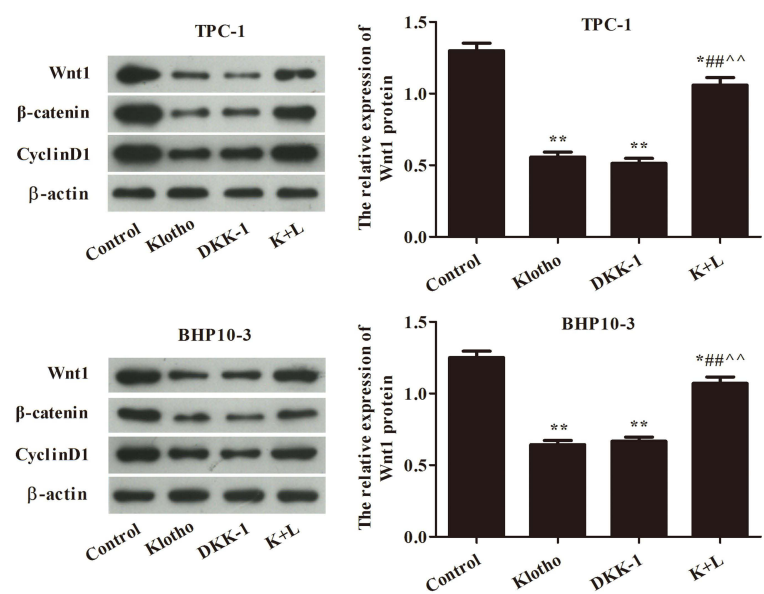

B
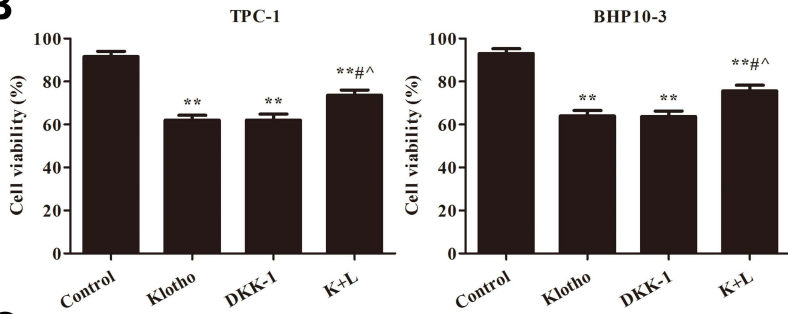

BHP10-3

C

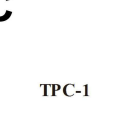

BHP10-3
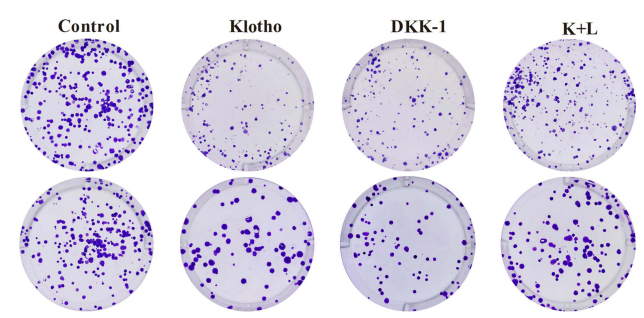

D

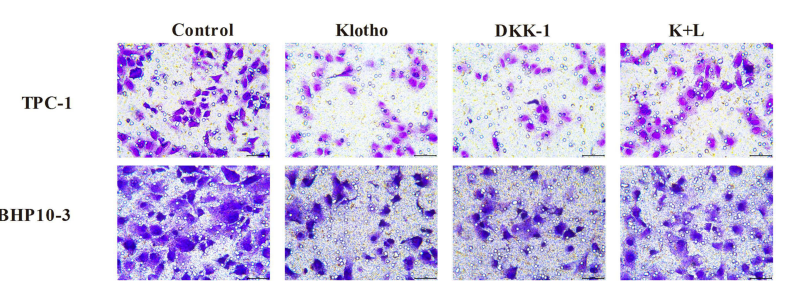

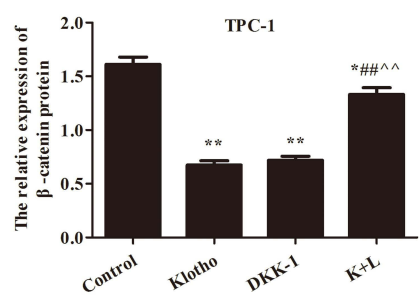
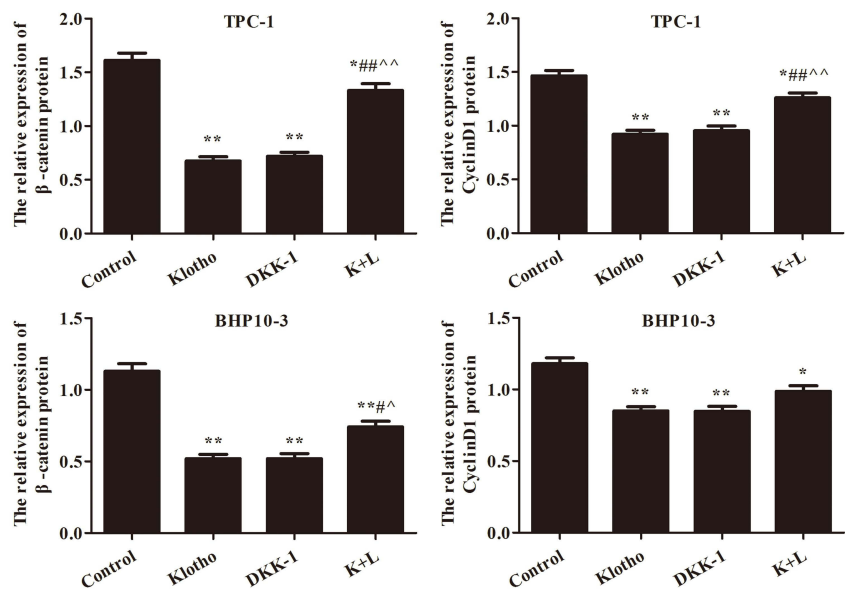
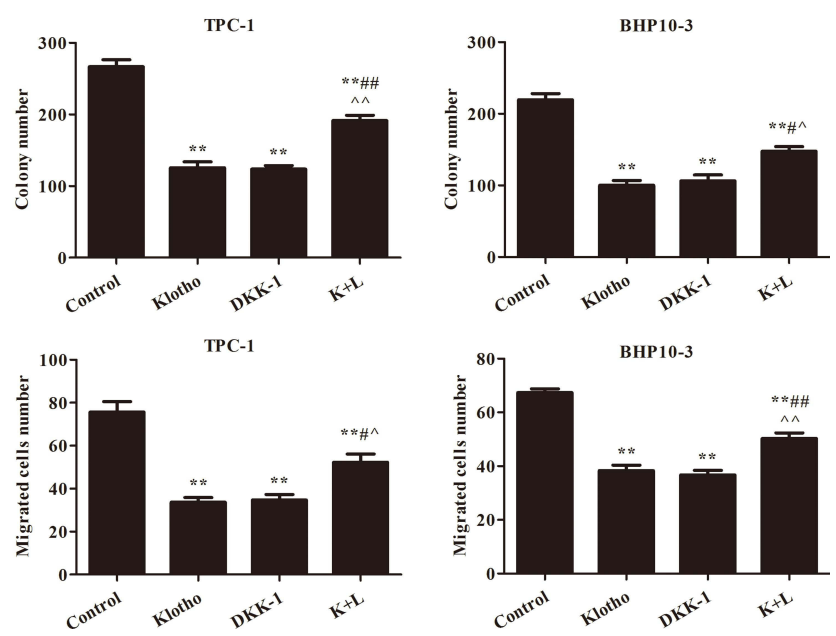

Figure 3 Klotho regulated the proliferation of TPC-I and BHPI0-3 cells via the Wnt/ $\beta$-catenin pathway. (A) Wnt/ $\beta$-catenin pathway-related proteins $W$ nt I, $\beta$-catenin, and CyclinDI were analyzed by Western blotting. (B) TPC-I and BHPI0-3 cell viabilities were analyzed by Cell Counting Kit (CCK)-8 assay. (C) TPC-I and BHPI0-3 cell proliferation was analyzed by plate colony formation assay. (D) TPC-I and BHPI0-3 cell migration was analyzed by Transwell assay ( $\times 400$ ). Compared to the control group, ${ }^{*} \mathrm{p}<0.05$, ${ }^{* *} \mathrm{p}<0.01$; compared to the Klotho group, ${ }^{\#} \mathrm{p}<0.05,{ }^{\# \#} \mathrm{p}<0.0 \mathrm{I}$; compared to the DKK-I group, ${ }^{\wedge}<0.05$, ${ }^{\wedge} \mathrm{p}<0.05$. Experiments were repeated three times and data are presented as mean \pm SD.

increased in the other groups compared to the control group $(p<0.05)$. Actionably, the apoptosis rate was significantly increased in the $\mathrm{K}+\mathrm{L}$ group compared to the Klotho group $(p<0.05)$. The expression of apoptosis-related proteins was also analyzed by Western blotting (Figure 4B). Compared to the control group, Bax and cleaved caspase- 3 expression was significantly increased, while Bcl-2 expression was significantly decreased, in the other groups $(\mathrm{p}<0.05)$. These results suggested that Klotho suppresses tumor growth in RET fusion models of PTC via activating the $\mathrm{Wnt} / \beta$-catenin pathway.

\section{Klotho Suppresses Tumor Growth via the Wnt/ $\beta$-Catenin Pathway}

To further confirm the mechanism of action of Klotho in the RET fusion model of PTC, mice with xenografts were used. As shown in Figure 5A-C, compared to the control group, the tumor volume and tumor weight were reduced 
A
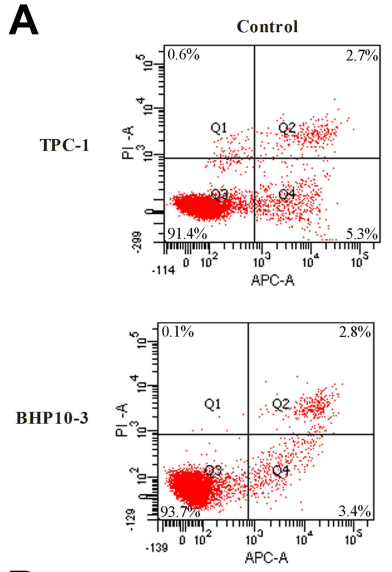

B
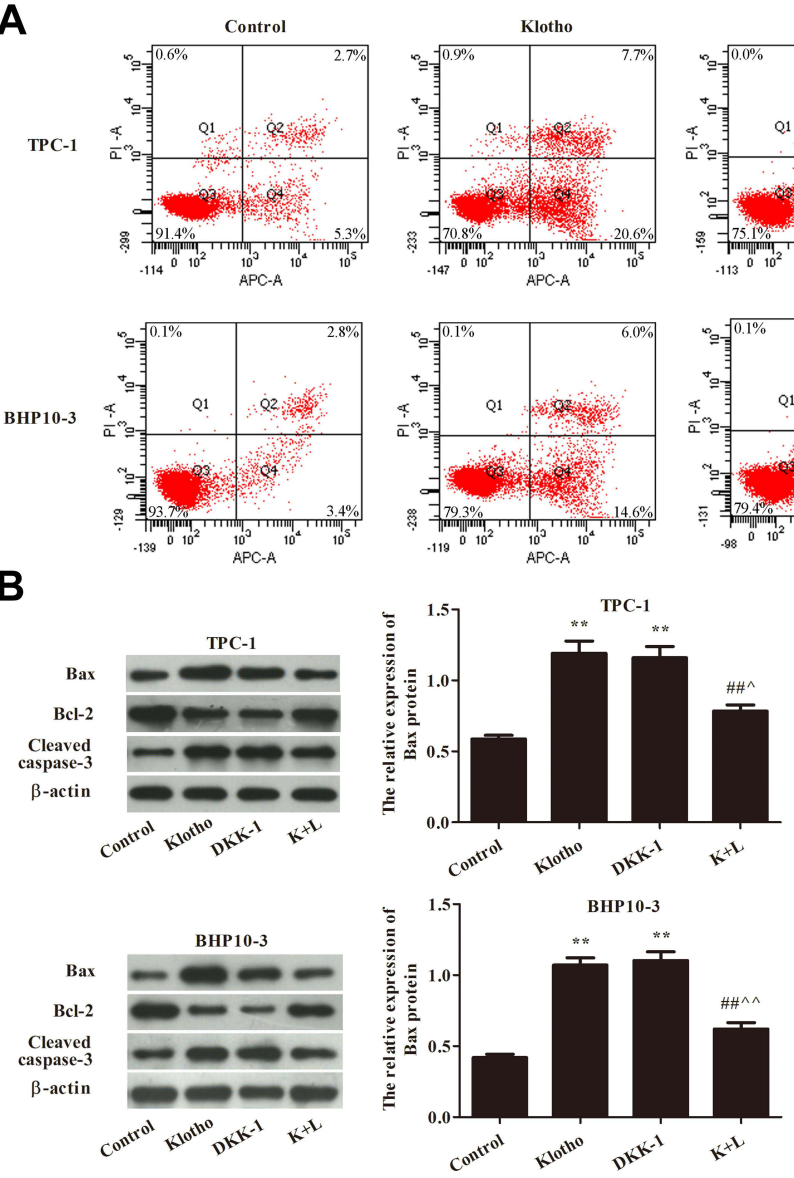
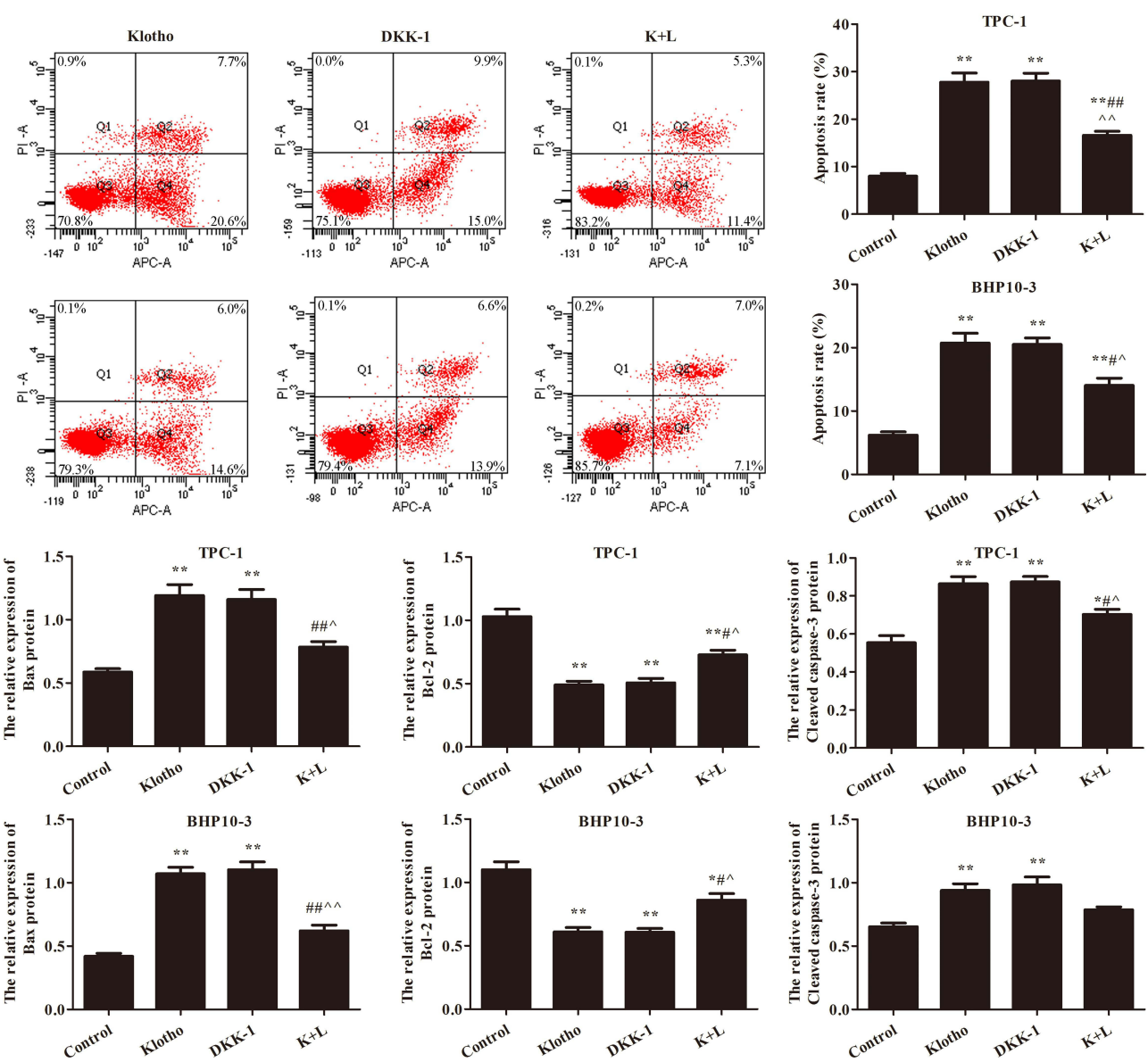

Figure 4 Klotho regulated the apoptosis of TPC-I and BHPI0-3 cells via the Wnt/B-catenin pathway. (A) Apoptosis was analyzed by flow cytometry. (B) Apoptosis-related proteins Bax, Bcl-2, and cleaved caspase- 3 were analyzed by Western blotting. Compared to the control group, ${ }^{*} p<0.05$, ** $p<0.01 ;$ compared to the Klotho group, $\#$ $p<0.05$, ${ }^{\#} \mathrm{p}<0.0$ I; compared to the DKK-I group, ${ }^{\wedge} \mathrm{p}<0.05,{ }^{\wedge} \mathrm{p}<0.05$. Experiments were repeated three times and data are presented as mean \pm SD.

in the other groups $(\mathrm{p}<0.05)$. Consistent with the in vitro results, the tumor volume and weight were significantly increased in the $\mathrm{K}+\mathrm{L}$ group compared to the Klotho group $(p<0.05)$. Ki-67 expression was also reduced in the tumor tissues of the other groups compared to the control group (Figure 5D, $\mathrm{p}<0.05$ ). Compared to the Klotho group, the percentage of Ki67-positive cells was significantly increased in the tumor tissues in the $\mathrm{K}+\mathrm{L}$ group $(p<0.05)$. These data further revealed that Klotho restrained proliferation in the in vivo RET fusion model of PTC via the Wnt/ $\beta$-catenin pathway.

\section{Klotho Promotes PTC Cell Apoptosis via the Wnt/ $\beta$-Catenin Pathway}

Apoptosis-related proteins were also analyzed by Western blotting (Figure 6A). Compared to the control group, Bax and cleaved caspase-3 expression was significantly increased, while $\mathrm{Bcl}-2$ expression was significantly decreased, in the other groups $(\mathrm{p}<0.05)$. Compared to the Klotho group, Bax and Cleaved caspase-3 expression was significantly decreased, while $\mathrm{Bcl}-2$ expression was significantly increased, in the $\mathrm{K}+\mathrm{L}$ group $(\mathrm{p}<0.05)$. Wnt $/ \beta$ catenin pathway-related protein expression was assessed in each group by Western blotting (Figure 6B). The results showed that Wnt1, $\beta$-catenin, and CyclinD1 expression was significantly decreased in the other groups compared to the control group $(p<0.05)$. However, Wnt1, $\beta$-catenin, and CyclinD1 expression was significantly increased in the $\mathrm{K}+\mathrm{L}$ group compared to the Klotho group $(\mathrm{p}<0.05)$. All data suggested that Klotho blocked cancer progression in the RET fusion models of PTC by regulating the $\mathrm{Wnt} / \beta$ catenin pathway.

\section{Discussion}

In our study, we found that Klotho expression was low in RET fusion models of PTC cells, which is similar to the results of previously published clinical research. In 


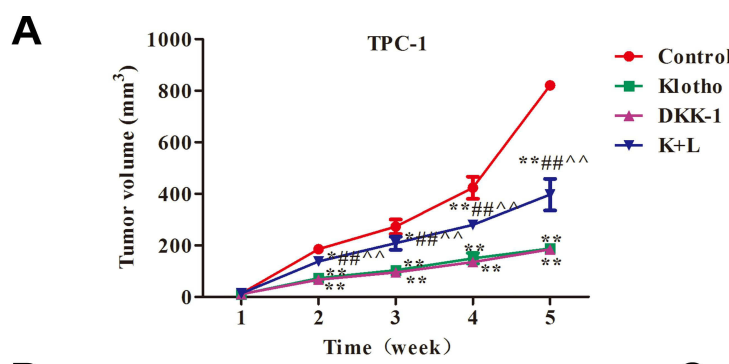

B

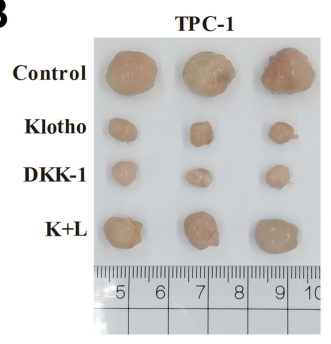

D

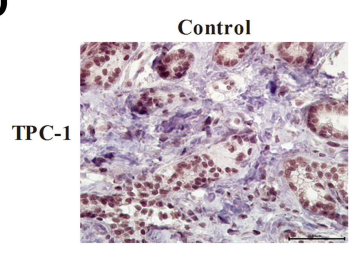

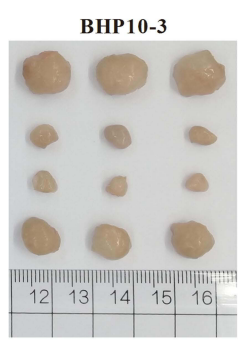

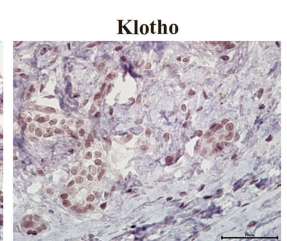

C

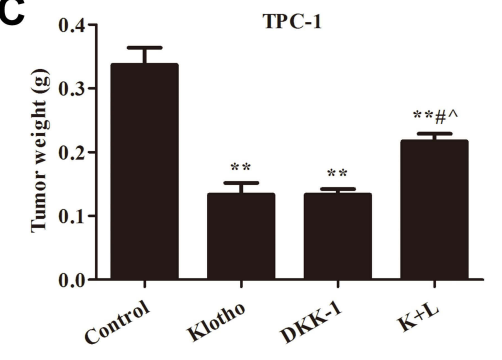

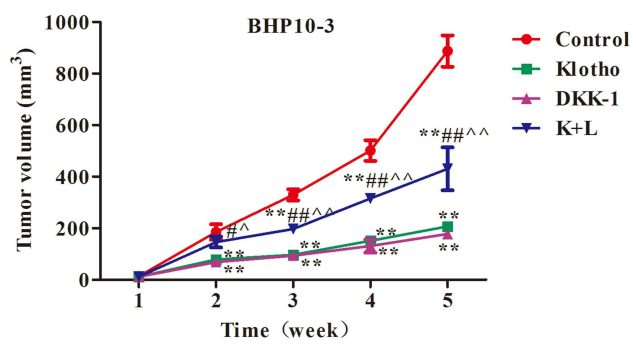
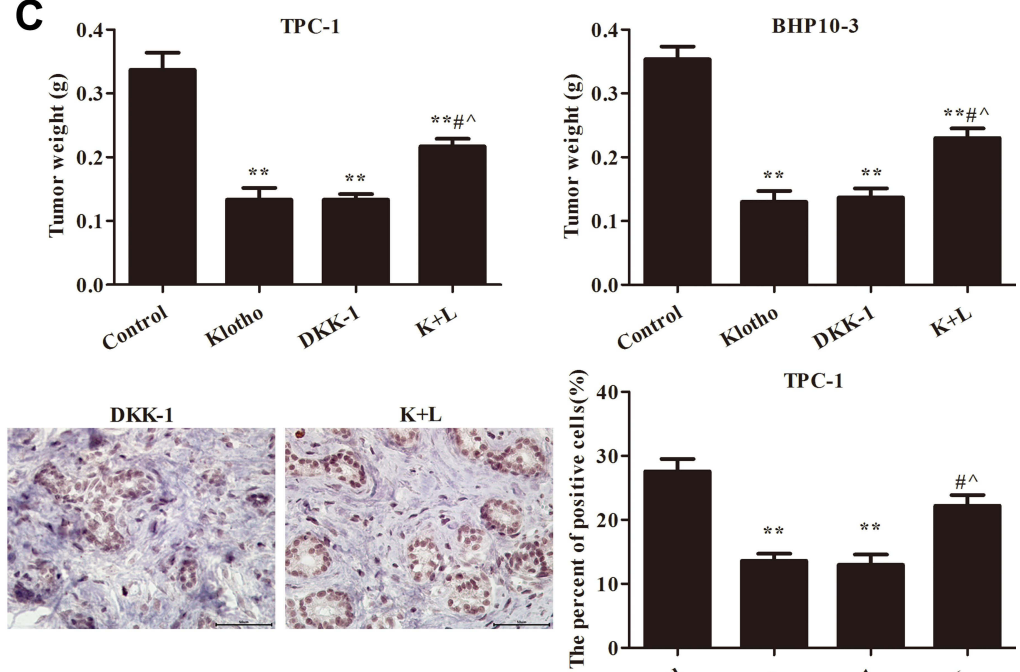

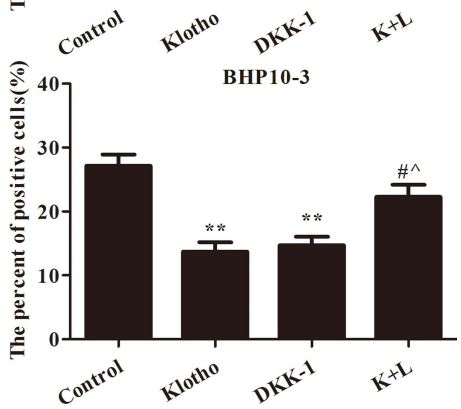

Figure 5 Klotho regulated tumor growth via the Wnt/B-catenin pathway. (A) Tumor volume; (B) tumor photograph; (C) tumor weight; (D) immunohistochemistry to detect Ki67 expression ( $\times 400)$. Compared to the control group, ${ }^{*} \mathrm{p}<0.05,{ }^{* *} \mathrm{p}<0.0 \mathrm{I}$; compared to the Klotho group, ${ }^{*} \mathrm{p}<0.05$, ${ }^{\#} \mathrm{p}<0.0 \mathrm{I}$; compared to the DKK-I group, $\hat{p}<0.05,{ }^{\wedge} \mathrm{p}<0.05$. Experiments were repeated three times and data are presented as mean $\pm \mathrm{SD}$.

patients with highly malignant thyroid cancers, Klotho expression was negative or low. ${ }^{10}$ Moreover, Dai et al reported that Klotho overexpression markedly reduced thyroid cancer FTC238 and FTC133 cell proliferation. ${ }^{19}$ In addition, our data showed Klotho overexpression inhibited cancer progression in the in vitro and in vivo RET fusion models of PTC. These findings further support the role of Klotho as an anti-tumor gene in human thyroid cancer. Klotho is known as an anti-tumor gene that acts as a circulating hormone to inhibit cancer cell proliferation and migration by modulating tumor-related signal transduction. ${ }^{9}$ Our results further reveal that Klotho has an anti-tumor role in RET fusion models of PTC, which a gap in thyroid carcinoma.
The expression of the apoptosis-related proteins Bax, Bcl-2, and cleaved caspase- 3 was assessed to further understand the mechanisms of action of Klotho in PTC. B-cell lymphoma-2 (Bcl-2), an anti-apoptotic protein, contains four Bcl-2 homology (BH) domains, and it is commonly associated with several malignancies. ${ }^{20}$ Bax regulates apoptosis by contributing to tumor regression, which is accomplished by interaction between the BH3cleft of Bcl-2 and the BH3 domain of Bax. ${ }^{20}$ Caspases are used as apoptosis-specific markers, as changes in their activity are related to stages of apoptosis. ${ }^{21}$ In particular, caspase-3 can directly induce apoptosis after being activated by activated caspase- 8 or -9 , and cleaved caspase- 3 has been extensively used to monitor apoptosis in tumor 

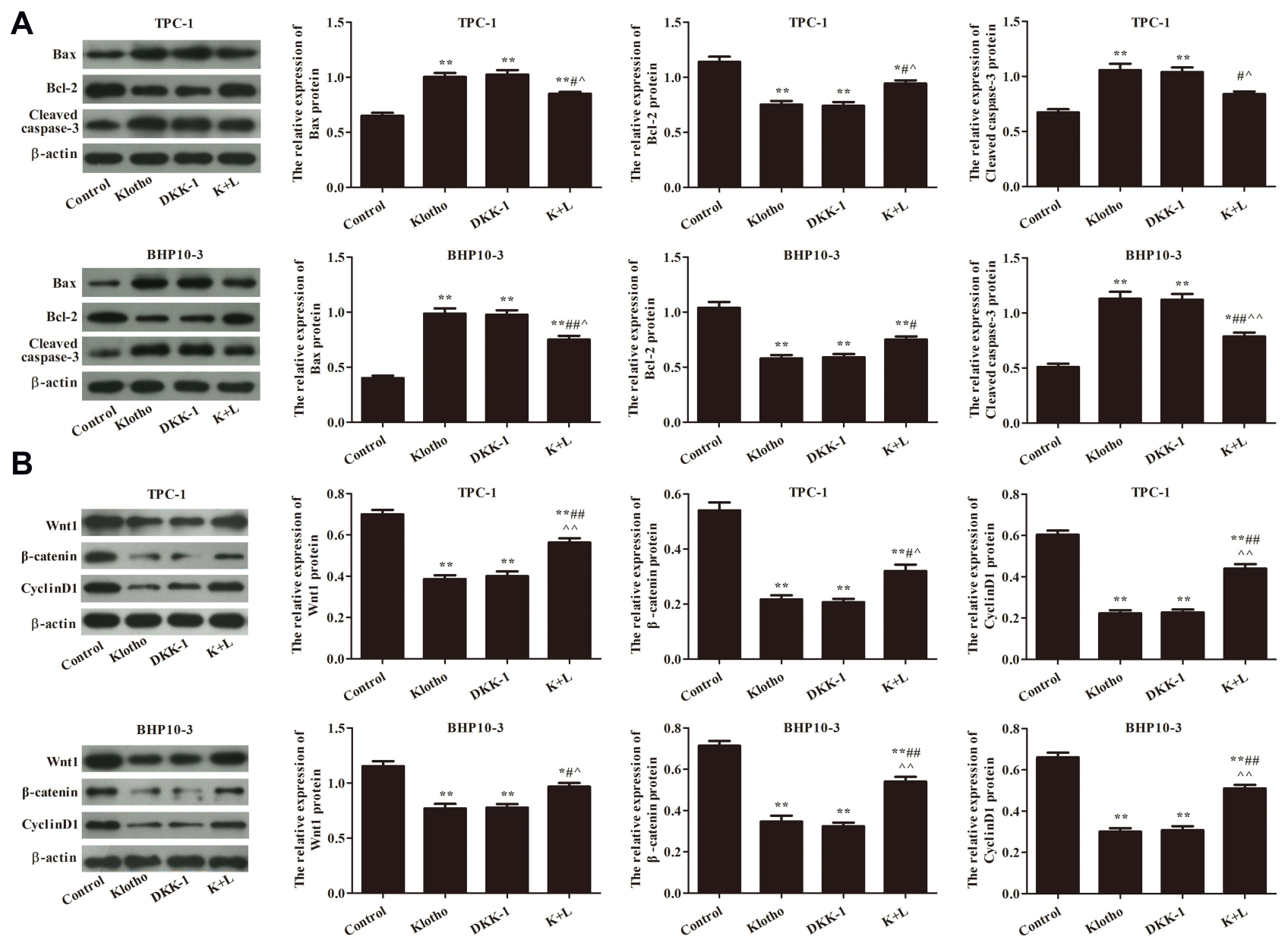

Figure 6 Klotho regulates PTC cell apoptosis via the Wnt/ $\beta$-catenin pathway. (A) Apoptosis-related proteins Bax, Bcl-2, and cleaved caspase-3 were analyzed by Western blotting. (B) Wnt/ $\beta$-catenin pathway-related proteins Wnt, $\beta$-catenin, and CyclinDI were analyzed by Western blotting. Compared to the control group, *p<0.05, ** $<<0.01$; compared to the Klotho group, ${ }^{\#} \mathrm{p}<0.05,{ }^{\#} \mathrm{p}<0.0$ I; compared to the DKK-I group, ${ }^{\wedge}<0.05,{ }^{\wedge} \mathrm{p}<0.05$. Experiments were repeated three times and data are presented as mean \pm SD

cells. ${ }^{21}$ In the present study, Klotho overexpression decreased Bcl-2 expression and increased Bax and cleaved-caspase-3 expression in TPC-1 and BHP10-3 cells. These data were consistent with the results that showed that Klotho overexpression promotes apoptosis in the RET fusion models of PTC.

Many studies have reported that Klotho operates by regulating the $\mathrm{Wnt} / \beta$-catenin pathway in various diseases, including cardiomyocyte hypertrophy, ${ }^{22}$ hepatocellular carcinoma, ${ }^{23}$ and liver cancer. ${ }^{24}$ In thyroid carcinoma, the $\mathrm{Wnt} / \beta$-catenin pathway plays a primary role in invasion and metastasis, and its alteration is a late event in thyroid cell transformation. In our study, Klotho overexpression inhibited Wnt1, $\beta$-catenin, and CyclinD1 expression in the RET fusion models of PTC. To confirm the association of Klotho with the Wnt/ $\beta$-catenin pathway, a Wnt pathway inhibitor (DKK1) and a Wnt pathway activator $(\mathrm{LiCl})$ were used to study the effect of
Klotho on the Wnt/ $\beta$-catenin pathway. The results showed that the effects of Klotho on proliferation and apoptosis were similar to the effects of DKK1 in the in vitro and in vivo RET fusion models of PTC. However, $\mathrm{LiCl}$ administration significantly attenuated the effects of Klotho. These data reveal that Klotho inhibits cancer progression in the RET fusion models of PTC by inhibiting the Wnt/ $\beta$-catenin pathway.

However, this study has several limitations. The regulatory mechanisms of Klotho underlying its effects on the proliferation and invasion in the RET fusion models of PTC are complicated and involve multiple signaling pathways, which require further study. Furthermore, the molecular mechanism of Klotho-mediated cell proliferation in other types of thyroid cancer cells needs further exploration. In summary, more investigations are needed to reveal potential pathways involved in the regulatory mechanism of Klotho in RET fusion models of PTC. 


\section{Conclusion}

In summary, Klotho is a tumor suppressor and Klotho overexpression inhibits proliferation and promotes apoptosis in RET fusion models of PTC. The underlying mechanism might be associated with the $\mathrm{Wnt} / \beta$-catenin pathway. Klotho is a potential target for developing new treatments for PTC involving RET fusion.

\section{Data Sharing Statement}

The datasets used and/or analyzed during the current study are available from the corresponding author on reasonable request.

\section{Ethics Approval and Consent to Participate}

The animal experiments followed the NIH guidelines (NIH Pub. No. 85-23, revised 1996) and were approved by the Animal Protection and Use Committee of Huai'an Second People's Hospital.

\section{Author Contributions}

QW and LJ carried out the experimental work and the data collection and interpretation. QW and YPZ participated in the design and coordination of the experimental work, and acquisition of data. LJ and JW participated in the study design, data collection, analysis of data, and preparation of the manuscript. QW and HFD participated in the study design, the analysis and interpretation of data, and manuscript drafting. All authors read and approved the final manuscript. All authors have agreed on the journal to which the title will be submitted. All authors reviewed and agreed on all version of the article before submission, during revision, the final version accepted for publication, and any significant changes introduced at the proofing stage. All authors agree to take responsibility and be accountable for the contents of the manuscript.

\section{Funding}

There is no funding to report.

\section{Disclosure}

The authors report no conflicts of interest in this work.

\section{References}

1. Maturo A, Tromba L, De Anna L, et al. Incidental thyroid carcinomas. A retrospective study. G Chir. 2017;38(2):94-101. doi:10.11138/gchir/ 2017.38.2.094
2. Raue F, Frank-Raue K. Thyroid cancer: risk-stratified management and individualized therapy. Clin Cancer Res. 2016;22 (20):5012-5021. doi:10.1158/1078-0432.ccr-16-0484

3. Elisei R, Pinchera A. Advances in the follow-up of differentiated or medullary thyroid cancer. Nat Rev Endocrinol. 2012;8(8):466-475. doi: $10.1038 /$ nrendo. 2012.38

4. Schweppe RE, Klopper JP, Korch C, et al. Deoxyribonucleic acid profiling analysis of 40 human thyroid cancer cell lines reveals cross-contamination resulting in cell line redundancy and misidentification. $J$ Clin Endocrinol Metab. 2008;93 (11):4331-4341. doi:10.1210/jc.2008-1102

5. Mencke R, Olauson H, Hillebrands JL. Effects of Klotho on fibrosis and cancer: a renal focus on mechanisms and therapeutic strategies. Adv Drug Deliv Rev. 2017;121:85-100. doi:10.1016/j. addr.2017.07.009

6. Davidov B, Shmulevich R, Shabtay A, Rubinek T, Wolf I. The hormone KL1: a regulator of breast cancer cell metabolism. Isr Med Assoc J. 2019;21(7):504.

7. Arbel Rubinstein T, Shahmoon S, Zigmond E, et al. Klotho suppresses colorectal cancer through modulation of the unfolded protein response. Oncogene. 2019;38(6):794-807. doi:10.1038/s41388-0180489-4

8. Fakhar M, Najumuddin N, Gul M, Rashid S. Antagonistic role of Klotho-derived peptides dynamics in the pancreatic cancer treatment through obstructing WNT-1 and Frizzled binding. Biophys Chem. 2018;240:107-117. doi:10.1016/j.bpc.2018.07.002

9. Xuan NT, Hai NV. Changes in expression of klotho affect physiological processes, diseases, and cancer. Iran J Basic Med Sci. 2018;21 (1):3-8.

10. Pawlikowski M, Pisarek H, Borkowska M, Winczyk K. Expression of $\alpha$-Klotho protein in human thyroid cancers - an immunohistochemical study. Endokrynol Pol. 2019;70(3):237-240. doi:10.5603/EP. a2019.0004

11. Nguyen VHL, Hough R, Bernaudo S, Peng C. Wnt/ $\beta$-catenin signalling in ovarian cancer: insights into its hyperactivation and function in tumorigenesis. J Ovarian Res. 2019;12(1):122. doi:10.1186/ s13048-019-0596-z

12. Wang X, Lu X, Geng Z, Yang G, Shi Y. LncRNA PTCSC3/miR-574$5 \mathrm{p}$ governs cell proliferation and migration of papillary thyroid carcinoma via Wnt/ $\beta$-catenin signaling. $J$ Cell Biochem. 2017;118 (12):4745-4752. doi:10.1002/jcb.26142

13. Yu S, Cao S, Hong S, et al. miR-3619-3p promotes papillary thyroid carcinoma progression via Wnt/ $\beta$-catenin pathway. Ann Transl Med. 2019;7(22):643. doi:10.21037/atm.2019.10.71

14. Cheng X, Xu X, Chen D, Zhao F, Wang W. Therapeutic potential of targeting the $\mathrm{Wnt} / \beta$-catenin signaling pathway in colorectal cancer. Biomed Pharmacother. 2019;110:473-481. doi:10.1016/j. biopha.2018.11.082

15. Krishnamurthy N, Kurzrock R. Targeting the Wnt/beta-catenin pathway in cancer: update on effectors and inhibitors. Cancer Treat Rev. 2018;62:50-60. doi:10.1016/j.ctrv.2017.11.002

16. Ye Y, Long X, Zhang L, et al. NTS/NTR1 co-expression enhances epithelial-to-mesenchymal transition and promotes tumor metastasis by activating the $\mathrm{Wnt} / \beta$-catenin signaling pathway in hepatocellular carcinoma. Oncotarget. 2016;7(43):70303-70322. doi:10.18632/ oncotarget.11854

17. Mao T, He C, Wu H, Yang B, Li X. Silencing lncRNA HOTAIR declines synovial inflammation and synoviocyte proliferation and promotes synoviocyte apoptosis in osteoarthritis rats by inhibiting Wnt/ $\beta$-catenin signaling pathway. Cell Cycle. 2019;18 (22):3189-3205. doi:10.1080/15384101.2019.1671716

18. Huang HM, Huang CC, Wang FS, Hung PL, Chang YC. Activating the $\mathrm{Wnt} / \beta$-catenin pathway did not protect immature retina from hypoxic-ischemic injury. Invest Ophthalmol Vis Sci. 2015;56 (8):4300-4308. doi:10.1167/iovs.14-16176 
19. Dai D, Wang Q, Li X, Liu J, Ma X, Xu W. Klotho inhibits human follicular thyroid cancer cell growth and promotes apoptosis through regulation of the expression of stanniocalcin-1. Oncol Rep. 2016;35 (1):552-558. doi:10.3892/or.2015.4358

20. Raghav PK, Kumar R, Kumar V, Raghava GPS. Docking-based approach for identification of mutations that disrupt binding between Bcl-2 and Bax proteins: inducing apoptosis in cancer cells. Mol Genet Genom Med. 2019;7(11):e910. doi:10.1002/mgg3.910

21. Shim MK, Yoon HY, Lee S, et al. Caspase-3/-7-specific metabolic precursor for bioorthogonal tracking of tumor apoptosis. Sci Rep. 2017;7(1):16635. doi:10.1038/s41598-017-16653-2

22. Yu L, Meng W, Ding J, Cheng M. Klotho inhibits angiotensin II-induced cardiomyocyte hypertrophy through suppression of the AT1R/beta catenin pathway. Biochem Biophys Res Commun. 2016;473(2):455-461. doi:10.1016/j.bbrc.2016.03.029
23. Tang X, Wang Y, Fan Z, et al. Klotho: a tumor suppressor and modulator of the Wnt/ $\beta$-catenin pathway in human hepatocellular carcinoma. Lab Invest. 2016;96(2):197-205. doi:10.1038/ labinvest.2015.86

24. Sun H, Gao Y, Lu K, et al. Overexpression of Klotho suppresses liver cancer progression and induces cell apoptosis by negatively regulating wnt/ $\beta$-catenin signaling pathway. World $J$ Surg Oncol. 2015;13:307. doi:10.1186/s12957-015-0717-0

\section{Publish your work in this journal}

Cancer Management and Research is an international, peer-reviewed open access journal focusing on cancer research and the optimal use of preventative and integrated treatment interventions to achieve improved outcomes, enhanced survival and quality of life for the cancer patient.
The manuscript management system is completely online and includes a very quick and fair peer-review system, which is all easy to use. Visit http://www.dovepress.com/testimonials.php to read real quotes from published authors. 